\title{
Eosinophilic Pleural Effusion Complicating Allergic Bronchopulmonary Aspergillosis
}

\author{
Austin N. Kirschner ${ }^{\mathrm{a}}$ Erica Kuhlmann ${ }^{\mathrm{a}}$ Tomasz J. Kuzniar ${ }^{\mathrm{b}}$ \\ ${ }^{a}$ Department of Medicine, and ${ }^{b}$ Division of Pulmonary and Critical Care Medicine, NorthShore University \\ HealthSystem, Evanston, III., USA
}

\section{Established Facts}

- Allergic bronchopulmonary aspergillosis (ABPA) typically presents in patients with history of asthma or cystic fibrosis with symptoms attributable to bronchial or peribronchial disease.

\section{Novel Insights}

- Eosinophilic pleural effusion may accompany ABPA.

- ABPA should be among differential diagnoses of eosinophilic pleural disease.

\section{Key Words}

Pleural effusion • Allergic bronchopulmonary aspergillosis • Empyema

\begin{abstract}
Allergic bronchopulmonary aspergillosis (ABPA) is primarily a disease of patients with cystic fibrosis or asthma, who typically present with bronchial obstruction, fever, malaise, and expectoration of mucus plugs. We report a case of a young man with a history of asthma who presented with cough, left-sided pleuritic chest pain and was found to have lobar atelectasis and an eosinophilic, empyematous pleural effusion. Bronchoscopy and sputum cultures grew Aspergillus fumigatus, and testing confirmed strong allergic response to
\end{abstract}

this mold, all consistent with a diagnosis of ABPA. This novel and unique presentation of ABPA expands on the differential diagnosis of eosinophilic pleural effusions.

Copyright $\odot 2011$ S. Karger AG, Basel

\section{Case Report}

A 25-year-old current smoker, electrician, with a history of well-controlled asthma not regularly using any medication, was sent to the hospital by his primary care provider for worsening cough, dyspnea on exertion, left-sided pleuritic chest pain and upper back pain, after failing antibiotic treatment for pneumonia diagnosed by chest X-ray 2 weeks prior. He had no history of fever, hemoptysis, weight loss, recent travel, or eating raw seafood. Clinical examination on admission demonstrated dullness to percussion and decreased breath sounds at left lung base. Complete

\section{KARGER}

Fax +41613061234

E-Mail karger@karger.ch

www.karger.com
(C) 2011 S. Karger AG, Basel

$0025-7931 / 11 / 0825-0478 \$ 38.00 / 0$

Accessible online at:

www.karger.com/res
Tomasz J. Kuzniar, MD, $\mathrm{PhD}$

Division of Pulmonary and Critical Care Medicine NorthShore University HealthSystem

2650 Ridge Avenue, Suite 5301, Evanston, IL 60201 (USA)

Tel. +1 847570 2714, E-Mail tkuzniar@ northshore.org 

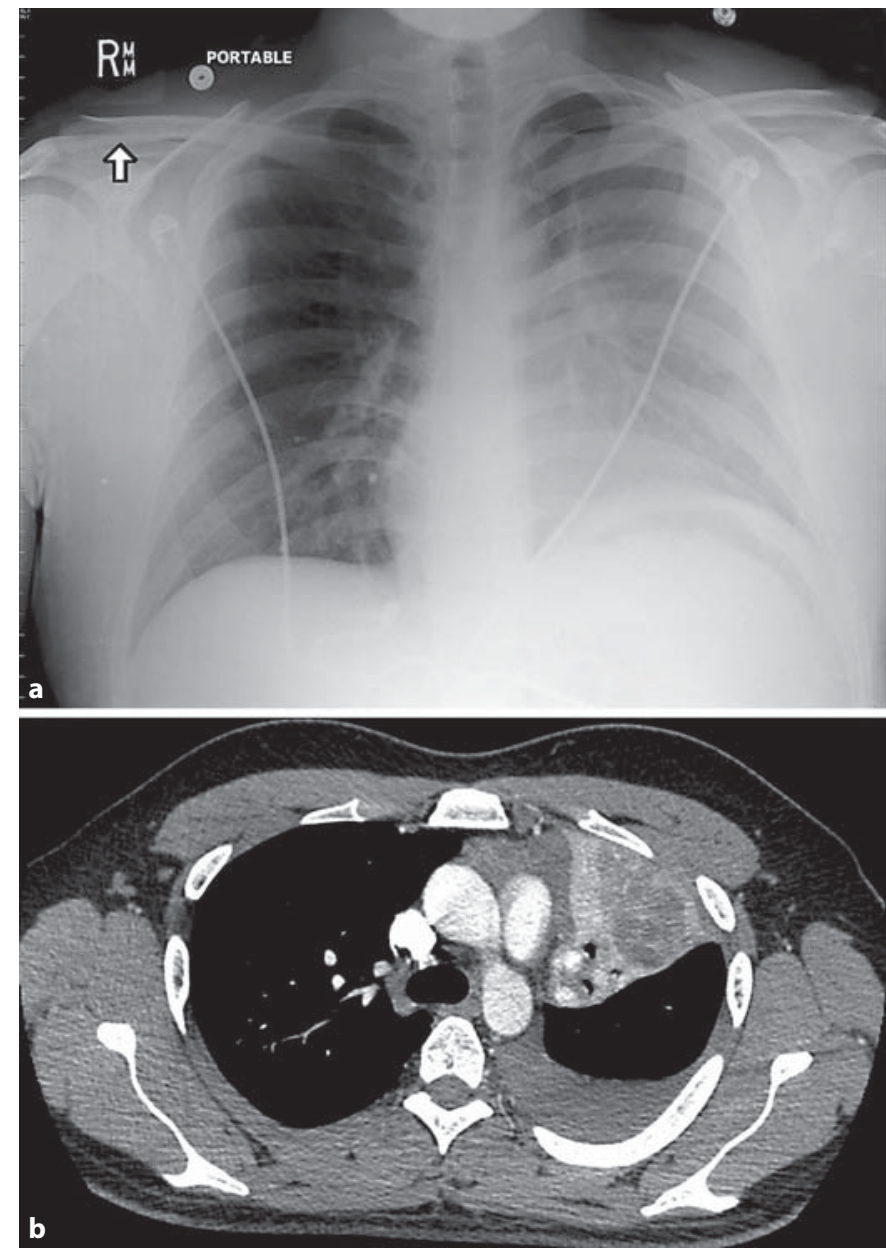

Fig. 1. Chest X-ray (a) and chest CT (b) at diagnosis showing left lower lobe atelectasis and pleural effusion.

blood count revealed a leukocytosis of $16,400 / \mu 1$ with marked eosinophilia (30\%, absolute eosinophil count of 4,900 $\mu \mathrm{l})$. Serum immunoglobulin E (IgE) level was 7,319 kU/1 (normal, <127), with Aspergillus-specific IgE of $65.5 \mathrm{kU} / \mathrm{l}$ and IgG of $>200 \mathrm{mg} / \mathrm{l}$. A chest $\mathrm{X}$-ray and a CT of the chest showed left upper lobe atelectasis and left pleural effusion (fig. 1a, b). Thoracentesis was performed and $800 \mathrm{ml}$ of opaque yellow fluid were removed. Laboratory analysis of pleural fluid revealed $\mathrm{pH}$ of 7.01, glucose of $5 \mathrm{mg} / \mathrm{dl}$, protein of $6.5 \mathrm{~g} / \mathrm{dl}$, lactate dehydrogenase of $1,409 \mathrm{IU} / 1$, and 50,800 nucleated cells (95\% eosinophils). Pleural fluid was negative for cultures of aerobic/anaerobic bacteria, parasites, fungi, and acid fast organisms; galactomannan enzyme immunoassay on pleural effusion was negative. Urine Legionella, Histoplasma, and Blastomyces antigens were negative.

Bronchoscopy was performed and a complete obstruction of the left upper lobe with brownish mucus plugs was seen. A bronchial wash was negative for Gram stain and bacterial culture, acid-fast bacilli smear and culture, direct fluorescent antibody for Legionella and Pneumocystis jirovecii. The bronchial wash was positive on smear and fungal culture for Aspergillus fumigatus.

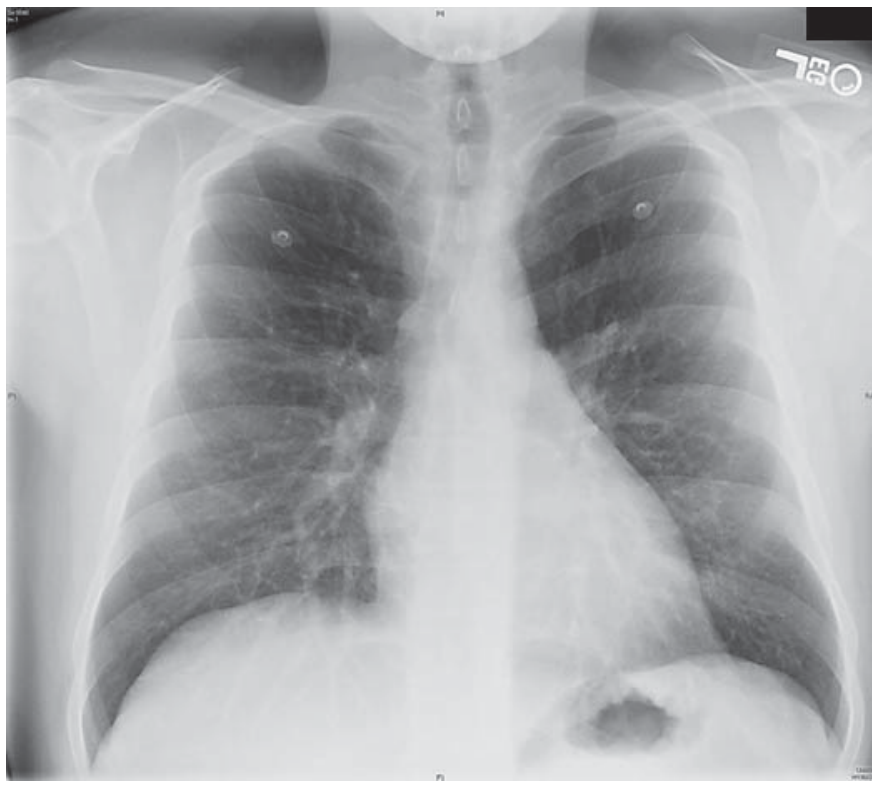

Fig. 2. Chest X-ray 6 months after the diagnosis showing resolution of the effusion and atelectasis.

Based on the above presentation, a diagnosis of allergic bronchopulmonary aspergillosis was made.

The patient was treated with prednisone at $40 \mathrm{mg} /$ day which were weaned over 3 months, voriconazole at $300 \mathrm{mg}$ twice daily, and inhaled fluticasone propionate/salmeterol $500 \mu \mathrm{g} / 50 \mu \mathrm{g}$ twice daily. At 6 months' follow-up, he was well and his chest radiograph normalized (fig. 2).

\section{Discussion}

ABPA is a complex hypersensitivity reaction, often in patients with asthma or cystic fibrosis, which occurs when bronchi become colonized by Aspergillus. Repeated episodes of bronchial obstruction, inflammation, and mucoid impaction can lead to bronchiectasis, fibrosis, and respiratory compromise [1]. The pathophysiology of ABPA involves Aspergillus-induced activation of Th2 CD4+ T cells that generate IL-4, IL-5, IL-13, and other cytokines, resulting in local and systemic inflammatory response with marked eosinophilia, and high IgE and IgG levels.

Most ABPA cases are diagnosed in the 3rd to 4 th decade of life. Common presenting findings include lowgrade fever, wheezing, bronchial hyperreactivity, hemoptysis, or productive cough. Some patients may expectorate brownish-black mucus plugs [2]. Imaging often reveals infiltrates, atelectasis due to mucus plugging, and bronchiectasis [3]. High-resolution chest CT can be used 
to distinguish between ABPA and asthma by the presence of bronchial dilatation, bronchiectasis, bronchial wall thickening, and pleural thickening, which are found more often in ABPA [4]. The major diagnostic criteria for ABPA are: history of asthma (or cystic fibrosis), serum total IgE concentration greater than $1,000 \mathrm{ng} / \mathrm{ml}$, elevated specific serum IgE and IgG to A. fumigatus, peripheral blood eosinophilia greater than $500 / \mathrm{mm}^{3}$, lung infiltrates on chest X-ray or CT, central bronchiectasis on chest CT, precipitating serum antibodies to A. fumigatus, and immediate skin test reaction to Aspergillus antigens. Supporting diagnostic criteria include repeated sputum samples containing Aspergillus, history of expectoration of brown plugs, and late skin reactivity to Aspergillus antigen. Our patient's diagnosis was established by his history of asthma, elevated serum total IgE and Aspergillusspecific $\operatorname{IgE}$ and $\operatorname{IgG}$, peripheral eosinophilia, imaging findings, and bronchoscopy findings [5].

Only 4 cases of pleural effusions associated with ABPA have been hitherto reported; in 3 cases in which thoracentesis was performed, the effusions were comprised predominantly of lymphocytes, mesothelial cells or neutrophils [6-8]. An eosinophilic pleural effusion has a broad differential that includes pleural irritation, malignancy, infections, pulmonary embolism, drug reactions, and other causes (table 1). To our knowledge, an eosinophilic effusion has not been reported in ABPA.

In our patient, an extensive search for a bacterial, fungal (including galactomannan antigen) or mycobacterial infection was negative; we therefore believe that the eosinophilic pleural effusion was a reflection of an intensive allergic response. Another possible pathological mechanism for development of an eosinophilic pleural effusion includes the translocation of fungi into the pleural space leading to local, pleural stimulation of a Th2-dependent inflammatory response. This mechanism could be investigated by measuring pleural fluid to serum gradients of IL-4, IL-5, IL-13 and IgE; in our case, no cytokine levels were obtained, but fungal cultures were negative. Alternatively, the eosinophilic pleural effusion could have formed due to local inflammatory mediators in the lung (e.g. IL-5) that entered the pleural cavity. An interesting feature of the presentation in our patient was its empyematous character, with low $\mathrm{pH}$, low glucose and high cellularity of the fluid; given an extraordinarily high eosinophil count in the fluid, these inflammatory features were likely related to high metabolic activity of these cells. Finally, a lobar collapse caused by Aspergillus-laden thick mucus plugs may have contributed to the development of 'ex vacuo' pleural effusion.
Table 1. Etiologies of eosinophilic pleural effusion (adapted from $[11,12])$

Pleural irritation

- Pneumothorax (within hours)

- Hemothorax (within days)

- Thoracic surgery/chest trauma/thoracoscopy

- Asbestos (within 2 decades)

Malignancy

- Lung cancer (most common)

Pulmonary embolism

Drugs (usually in months, but may be days to years)

- Common: warfarin, propylthiouracil, sulfasalazine, fenfluramine, dexfenfluramine, practolol, simvastatin, nitrofurantoin, isotretinoin, clozapine, mesalamine, trimipramine, acebutolol

- Uncommon: valproic acid, fluoxetine, acyclovir, tizanidine, dantrolene, crack cocaine, bromocriptine, vitamin $\mathrm{B}_{5} / \mathrm{H}$, infliximab, imidapril, gliclazide

Infections

- Bacteria

- Fungi

- Mycobacteria

- Parasites (e.g. paragonimiasis is most common, others include sparganosis, toxocariasis, cutaneous myiasis, loiasis, lymphatic filariasis, amebiasis, ascariasis, strongyloidiasis, echinococcosis, and dracunculiasis)

- Viruses

Chronic eosinophilic pneumonia

Rheumatoid pleural effusion

Churg-Strauss syndrome

Idiopathic

The mainstay of treatment of ABPA involves glucocorticoids and antifungal agents, such as itraconazole or voriconazole [5]. The addition of itraconazole to steroid medication was demonstrated as superior to steroid alone in two double-blind, randomized, placebo-controlled trials $[9,10]$. The combination treatment allows reduction in steroid dose and duration, helping to decrease the harmful side effects of long-term steroid administration, while maintaining improvement in pulmonary function and decreasing inflammatory parameters. With a 4-month treatment with prednisone, inhaled steroid/ bronchodilator, and voriconazole, our patient experienced a full resolution of symptoms.

\section{Financial Disclosure and Conflicts of Interest}

The authors have nothing to disclose. 


\section{References}

$>1$ Hoshino H, Tagaki S, Kon H, Shibusa T, Takabatake H, Fujita A, Sekine K, Abe S: Allergic bronchopulmonary aspergillosis due to Aspergillus niger without bronchial asthma. Respiration 1999;66:369-372.

$>2$ Riscili BP, Wood KL: Noninvasive pulmonary Aspergillus infections. Clin Chest Med 2009;30:315-335, vii.

-3 Thompson BH, Stanford W, Galvin JR, Kurihara Y: Varied radiologic appearances of pulmonary aspergillosis. Radiographics 1995; 15:1273-1284.

4 Angus RM, Davies ML, Cowan MD, McSharry C, Thomson NC: Computed tomographic scanning of the lung in patients with allergic bronchopulmonary aspergillosis and in asthmatic patients with a positive skin test to Aspergillus fumigatus. Thorax 1994; 49:586-589.
5 Walsh TJ, Anaissie EJ, Denning DW, Herbrecht R, Kontoyiannis DP, Marr KA, Morrison VA, Segal BH, Steinbach WJ, Stevens DA, van Burik JA, Wingard JR, Patterson TF: Treatment of aspergillosis: clinical practice guidelines of the infectious diseases society of America. Clin Infect Dis 2008;46:327360 .

6 Murphy D, Lane DJ: Pleural effusion in allergic bronchopulmonary aspergillosis: two case reports. Br J Dis Chest 1981;75:91-95.

7 Panchal N, Bhagat R, Pant C, Shah A: Allergic bronchopulmonary aspergillosis: the spectrum of computed tomography appearances. Respir Med 1997;91:213-219.

-8 O’Connor TM, O’Donnell A, Hurley M, Bredin CP: Allergic bronchopulmonary aspergillosis: a rare cause of pleural effusion. Respirology 2001;6:361-363.
9 Wark PA, Hensley MJ, Saltos N, Boyle MJ, Toneguzzi RC, Epid GD, Simpson JL, McElduff P, Gibson PG: Anti-inflammatory effect of itraconazole in stable allergic bronchopulmonary aspergillosis: a randomized controlled trial. J Allergy Clin Immunol 2003;111:952-957.

10 Stevens DA, Schwartz HJ, Lee JY, Moskovitz BL, Jerome DC, Catanzaro A, Bamberger DM, Weinmann AJ, Tuazon CU, Judson MA, Platts-Mills TA, DeGraff AC Jr: A randomized trial of itraconazole in allergic bronchopulmonary aspergillosis. N Engl J Med 2000;342:756-762.

11 Kalomenidis I, Light RW: Pathogenesis of the eosinophilic pleural effusions. Curr Opin Pulm Med 2004;10:289-293.

12 Huggins JT, Sahn SA: Drug-induced pleural disease. Clin Chest Med 2004;25:141-153. 